\title{
Molecular identification of redfish (genus Sebastes) in the White Sea indicates patterns of introgressive hybridisation
}

\author{
Peter Shum ${ }^{1}\left[\right.$ Christophe Pampoulie ${ }^{2}$ (i)
}

Received: 3 April 2020 / Revised: 3 July 2020 / Accepted: 11 July 2020 / Published online: 27 July 2020

(c) The Author(s) 2020

\begin{abstract}
The rare occurrence of redfish (genus Sebastes) in the White Sea encouraged Rolskii et al. (Polar Biol 43:385-389, 2020) to investigate the species identity of two animals captured near the Sredniy Island at $40 \mathrm{~m}$ depth. They reported that their morphological description proved unreliable and that genetic evidence "clearly demonstrated" these redfish belong to $S$. norvegicus. This was inferred using the S7 and the mitochondrial control region genes. However, while their S7 matched one $S$. norvegicus reference sequence, the $S$. norvegicus mitochondrial reference sequences used to infer species identity were previously shown to cluster with $S$. mentella. Therefore, both of their redfish samples belong to a $S$. norvegicus $\times S$. mentella (deep-pelagic) hybrid which presents an interesting perspective into the complex species dynamics in this group.
\end{abstract}

Keywords Sebastes $\cdot$ redfish · hybridisation $\cdot$ White Sea

North Atlantic (NA) Sebastes are remarkably similar in external appearance and the absence of clear diagnostic morphological characters can obscure an accurate species assessment whereby phenotypic plasticity and hybridisation has blurred morphological limits of detection (Pampoulie and Daníelsdóttir 2008; Christensen et al. 2018). Therefore, it is reasonable to expect that misidentification occurs regularly and the resulting conclusions are hindered by taxonomic bias. Artamonova et al. (2013) documented some of the earliest mitochondrial DNA control region (or D-loop) sequence records for NA Sebastes from a small collection of samples. They characterised species, and subsequently sequence records, according to geographic distribution, morphology and allozyme analysis. However, they were

This is a comment to Rolskii, A.Y., Artamonova, V.S. and Makhrov, A.A., 2020. Molecular identification ofgolden redfish (Sebastes norvegicus) in the White Sea. Polar Biology, pp.1-5. DOI:https://doi.org/10.1007/s00300-020-02629-y

Peter Shum

p.shum@1jmu.ac.uk

Christophe Pampoulie

christophe.s.pampoulie@hafogvatn.is

1 School of Biological and Environmental Sciences, Liverpool John Moores University, Liverpool L3 3AF, UK

2 Marine and Freshwater Research Institute, Fornubúðir 5, 220 Hafnarfjörður, Iceland unable to unambiguously separate $S$. mentella from $S$. norvegicus based on their allozyme analysis and morphological assessments have been known to be ambiguous (Pampoulie and Daníelsdóttir 2008). Later, Shum et al. (2015) greatly expanded the mitochondrial D-loop sequence record by investigating the phylogeographic distribution of $S$. mentella in the NA, and screened over 250 samples generating 55 mitochondrial D-loop haplotypes as well as reference sequences (verified using microsatellite \& mitochondrial DNA) for S. viviparus, S. fasciatus and S. norvegicus. In a following seafood authentication study, Shum et al. (2017) used all publicly available NA Sebastes mitochondrial D-loop sequences to identify redfish marketed in Europe and observed a common pattern: all previously published $S$. norvegicus sequences (Hyde and Vetter 2007; Artamonova et al. 2013) consistently clustered within $S$. mentella. They concluded that morphological misidentification may have led to inaccurate reference sequences deposited in public databases.

A prerequisite for the molecular identification of species using a DNA barcode is the generation of a reliable database containing all available reference sequences attributed to accurately identified taxonomic species (Hebert et al. 2003). Rolskii and colleagues noted the inadequacy of using a universal barcode, such as the cytochrome oxidase I, as it presents a challenge to discriminate between recently diverged species (Steinke et al. 2009), and this was 


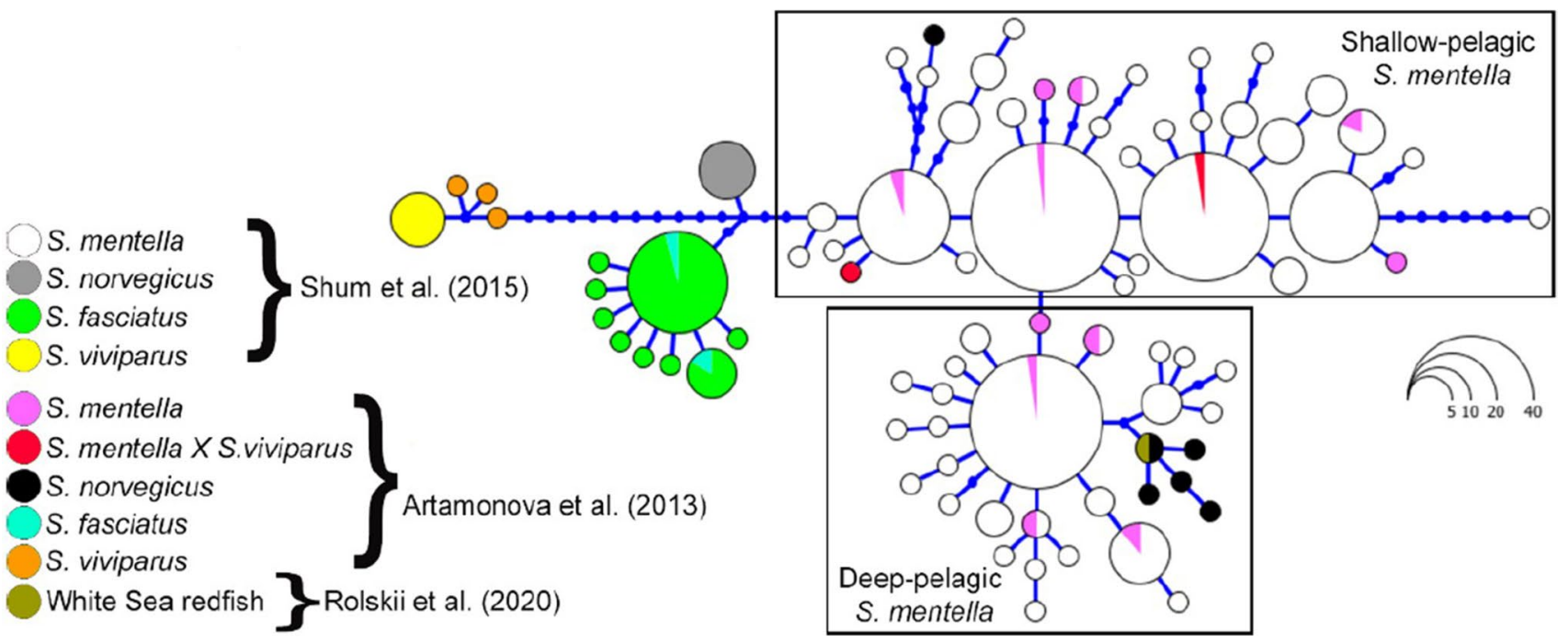

Fig. 1 Haplotype genealogy of North Atlantic Sebastes spp. from Shum et al. (2015) using mitochondrial DNA control region. Data from Artamonova et al. (2013) is visualised among reference haplo-

recently corroborated for NA Sebastes species (Shum et al. 2017). To identify the two redfish individuals caught in the White Sea, Rolskii et al. (2020) shifted their attention to using a more informative mitochondrial marker and found that the two samples collected had identical haplotypes of the mitochondrial D-loop and were in complete agreement with the D-loop haplotype 'MR1' previously identified by Artamonova et al. (2013) as S. norvegicus. However, this haplotype unambiguously clustered with $S$. mentella (Shum et al. 2017), which suggested taxonomic misidentification prior to genetic analyses. To unravel the correct identity of the White Sea redfish samples collected by Rolskii et al. (2020), we present a network analysis with appropriate reference sequences and include Artamonova et al. (2013) D-loop data using a maximum likelihood phylogenetic framework (hapview, Salzburger et al. 2011). We confirmed that the White Sea redfish samples possessed a mitochondrial D-loop sequence identical to the MR1 haplotype which we previously identified as S. mentella (Fig. 1; Shum et al. 2015). Therefore, based on Rolskii et al. (2020) assessment of the S7 and evidence from the mitochondrial DNA control region based on Shum et al. (2015), the correct species identification is that of a $S$. norvegicus $\times$ deep-pelagic $S$. mentella hybrid.

Genetic data are frequently used to delimit species because traditional methods used to identify species are constrained by the exclusive reliance on morphological characters which can underestimate diversity by failing to detect cryptic taxa. Therefore, a critical review of all available data will have the greatest resolution, particularly when hybridisation is widespread, species are morphologically very similar and divergence occurred more recently (Pampoulie and types where their $S$. norvegicus haplotypes cluster with shallow and deep-pelagic $S$. mentella. White Sea redfish collected by Rolskii et al. (2020) grouped with deep-pelagic $S$. mentella

Daníelsdóttir 2008; Shum et al. 2015). Misidentification of Sebastes spp. remains a challenge for scientists, and there is, therefore, an urgent need to standardise the collection of new samples and deposition of reference sequences in public databases and ideally expand on current knowledge on this lineage using a more exhaustive genomic coverage.

The occurrence of hybrid redfish in the White Sea presents an interesting scenario for North Atlantic Sebastes. Rolskii et al. (2020) indicated that the ambiguous meristic characters could be attributed to local conditions or a result from biological isolation of the White Sea due to differences in diagnostic features and depth distribution that are typical of $S$. norvegicus. Interestingly, we revealed the identity of $S$. norvegicus $\times$ deep-pelagic $S$. mentella hybrids, which allows opportunities to consider novel explanations for ecomorphological traits observed in these redfish in such an unusual environment. Hybridisation is known to act as a generative force, facilitating adaptive evolution via introgression or promoting diversification through hybrid speciation (Mallet 2007). Given the substantial impact of hybridisation in this genus (Saha et al. 2017; Schwenke et al. 2018), it would seem prudent not to ignore such remarkable findings.

Open Access This article is licensed under a Creative Commons Attribution 4.0 International License, which permits use, sharing, adaptation, distribution and reproduction in any medium or format, as long as you give appropriate credit to the original author(s) and the source, provide a link to the Creative Commons licence, and indicate if changes were made. The images or other third party material in this article are included in the article's Creative Commons licence, unless indicated otherwise in a credit line to the material. If material is not included in the article's Creative Commons licence and your intended use is not permitted by statutory regulation or exceeds the permitted use, you will 
need to obtain permission directly from the copyright holder. To view a copy of this licence, visit http://creativecommons.org/licenses/by/4.0/.

\section{References}

Artamonova VS, Makhrov AA, Karabanov DP, Rolskiy AY, Bakay YI, Popov VI (2013) Hybridization of beaked redfish (Sebastes mentella) with small redfish (Sebastes viviparus) and diversification of redfish (Actinopterygii: Scorpaeniformes) in the Irminger Sea. J Nat Hist 47:1791-1801. https://doi.org/10.1080/00222 933.2012.752539

Christensen HT, Rigét F, Backe MB, Saha A, Johansen T, Hedeholm RB (2018) Comparison of three methods for identification of redfish (Sebastes mentella and S. norvegicus) from the Greenland east coast. Fish Res 201:11-17. https://doi.org/10.1016/j.fishr es.2018.01.003

Hebert PDN, Ratnasingham S, DeWaard JR (2003) Barcoding animal life: cytochrome $\mathrm{c}$ oxidase subunit 1 divergences among closely related species. Proc R Soc B 270:S96-S99. https://doi. org/10.1098/rsbl.2003.0025

Hyde J, Vetter RD (2007) The origin, evolution, and diversification of rockfishes of the genus Sebastes (Curvier). Mol Phylogenet Evol 44:790-811. https://doi.org/10.1016/j.ympev.2006.12.026

Mallet J (2007) Hybrid speciation. Nature 446:279-283. https://doi. org/10.1038/nature05706

Pampoulie C, Daníelsdóttir AK (2008) Resolving species identification problems in the genus Sebastes using nuclear genetic markers. Fish Res 93:54-63. https://doi.org/10.1016/j.fishres.2008.02.007

Rolskii AY, Artamonova VS, Makhrov AA (2020) Molecular identification of golden redfish (Sebastes norvegicus) in the White
Sea. Polar Biol 43:385-389. https://doi.org/10.1007/s00300-02002629-y

Saha A, Johansen T, Hedeholm R, Nielsen EE, Westgaard JI, Hauser L, Planque B, Cadrin SX, Boje J (2017) Geographic extent of introgression in Sebastes mentella and its effect on genetic population structure. Evol Appl 10:77-90. https://doi.org/10.1111/eva.12429

Salzburger W, Ewing GB, Haeseler A (2011) The performance of phylogenetic algorithms in estimating haplotype genealogies with migration. Mol Ecol 20:1952-1963. https://doi.org/10.1111/ j.1365-294X.2011.05066.x

Schwenke PL, Park LK, Hauser L (2018) Introgression among three rockfish species (Sebastes spp.) in the Salish Sea, northeast Pacific Ocean. PLoS ONE 13:e0194068. https://doi.org/10.1371/journ al.pone. 0194068

Shum P, Moore L, Pampoulie C, Di Muri C, Vandamme S, Mariani $S$ (2017) Harnessing mtDNA variation to resolve ambiguity in 'Redfish' sold in Europe. PeerJ 5:e3746. https://doi.org/10.7717/ peerj.3746

Shum P, Pampoulie C, Kristinsson K, Mariani S (2015) Three-dimensional post-glacial expansion and diversification of an exploited oceanic fish. Mol Ecol 24:3652-3667. https://doi.org/10.1111/ mec. 13262

Steinke D, Zemlak TS, Boutillier JA, Hebert PDN (2009) DNA barcoding Pacific Canada's fishes. Mar Biol 156:2641-2647. https://doi. org/10.1007/s00227-009-1284-0

Publisher's Note Springer Nature remains neutral with regard to jurisdictional claims in published maps and institutional affiliations. 